\title{
Developmental Prevention in a Disadvantaged Community
}

\author{
Ross Homel*, Gordon Elias** and Ian Hay** \\ * Professor, School of Criminology and Criminal Justice \& Deputy \\ Director, Key Centre for Ethics, Law, Justice and Governance, \\ Griffith University \\ ** Senior Lecturers, School of Cognition, Language and Special \\ Education, Griffith University
}

\section{Published in:}

Eckersley, R., Dixon, J. \& Douglas, R. (Eds., 2001), The Social Origins of Health and Well-being: From the Planetary to the Molecular (pp. 269-279), Melbourne:

Cambridge University Press. 


\begin{abstract}
Disadvantaged communities have special needs and should be the target of specialised programs that have as their focus not just individuals and families but also neighbourhood characteristics. This is because the creation of child- and adolescentfriendly communities has promise as a way of reducing crime and related problems. Thus a major challenge is to implement in disadvantaged communities a package of evidence-based programs that influence multiple risk and protective factors, but in a way that not simply involves but empowers local residents and changes developmentally relevant institutions and social policies. One way of thinking about how to do this is to combine the insights of developmental prevention and community development.
\end{abstract}

Developmental prevention involves intervention early in developmental pathways that lead to crime and related problems, emphasising investment in "child friendly" institutions, communities and social policies and the manipulation of multiple risk and protective factors at different levels of the social ecology and at crucial transition points, such as around birth, the commencement of school, or graduation from primary to high school. Community development workers seek through participatory processes to redress inequality and exclusion, with a focus on groups seen to be marginalised socioeconomically, culturally or politically.

In this paper we describe the theoretical basis for, and the development of, a prevention project in a disadvantaged community in Brisbane. A major focus of this project is the transition from family to school. A specific aim is to improve the readiness of children for school. Selection of programs is being guided by the audit published in Pathways to Prevention (currently being updated) as well as by a "bottom 
up” process of consultation and observation, including participatory data collection in indigenous and other ethnic groups. We envisage a set of programs divided into two broad, closely inter-related categories: family programs and preschool/ school programs.

The family programs are conceptualised as consisting of overlapping layers, moving from informal, broad-based programs such as play groups, parenting training, and education forums, to formal support services such as parenting support groups or toy libraries, through to intensive family support and assistance, such as individual and family counselling (including intensive work with families with one or more members in jail or juvenile detention). School-based programs will probably be similar to those developed for the Schools as Community Centres Program in New South Wales. One specific program being planned involves communication enhancement groups in a number of preschools. These groups will involve parents with their preschool children and will focus on the development of communication skills in play, conversational and book-reading contexts. Allied to this, play groups with similar language and communication goals will be conducted for younger children with their mothers. 


\section{The Need for a Focus on Disadvantaged Communities}

Crime and violence have been near the top of the political agenda in Australia for the past quarter century. The main response has been punishment - more police and more prisons. Slammed doors and a one-way ticket to 'somewhere else' characterise this time-hallowed and universally popular reaction to malignancy and turpitude.

In the last decade, a number of related problems with a more obvious 'health' flavour have risen in the charts. These problems, which include illicit drug abuse (manifested particularly in deaths from 'overdoses') and child behaviour problems, have not dislodged punishment from its pre-eminent position - indeed, in some respects they have entrenched its use - but they have had the singular virtue of at least opening the door to a public health policy response.

Drug abuse well illustrates this point. Harm minimisation was, after a brief struggle, accepted in 1985 in Australia (but not the United States) as the over-riding principle informing national drug strategy (Homel \& Bull, 1996). For this reason, it has been harder for governments faced with the drug problem simply to diagnose moral failing and prescribe law enforcement and punishment, notwithstanding recent trends. Harm minimisation requires some focus on prevention and at least a nodding acquaintance with risk and protective factors, something that until recently has been notably lacking from the crime arena (Developmental Crime Prevention Consortium, 1999). More generally, the emerging evidence that much the same risk and protective factors underlie juvenile crime, child behaviour problems, mental and physical health, injury and drug use (Davison et al., 2000; Durlak, 1998; Marshall \& Watt, 1999) 
strongly suggests that there should be 'joined up solutions' to such 'joined up problems.'

The rise to prominence of crime and health problems in a period of great economic prosperity perhaps illustrates “modernity’s paradox” (Keating \& Hertzman, 1999, p. 1) - improving economic indicators combined with deteriorating indicators of health and wellbeing, particularly for children and youth. Although evidence for deteriorating outcomes in Australia is patchy (Zubrick et al., 1999), available data do indicate that the health and well-being of children and young people in Australia and in other developed countries at the end of the twentieth century is worse than it was in the 1950s and 60s (Eckersley, 1998; Rutter \& Smith, 1995a). Most of the damage appears to have been done in the 1970s and 1980s, with less marked negative trends in the 90s in some indicators such as serious assaults (Eckersley, 1998; Homel \& Mirrlees-Black, 1997).

An intensifying 'gradient effect' (a steepening relationship over time between socioeconomic status and outcomes such as literacy or life expectancy) is advanced by Keating \& Hertzman (1999) and others as one explanation for the trends. Other hypotheses focus on the increased prevalence of family risk factors such as parental conflict, separation and neglect; changes in adolescent transitions (eg, increased isolation of young people from adults as the result of a stronger youth culture); and cultural shifts (eg, breakdown in frameworks providing values, purpose, and a sense of belonging) (Rutter \& Smith, 1995b).

Evidence for the social gradient hypothesis seems largely lacking in Australia. It is not even clear that all relevant distances along the horizontal axis (ie. variation in socioeconomic status) have increased. For example, while a number of studies do 
suggest an increasing gap between upper and middle-income families (eg, Harding, 1997; 2000), this does not necessarily mean that more children are living in poverty. If the Henderson poverty line is used, the percentage of children in poverty has certainly increased markedly in the past 25 years (Harding \& Szukalska, 1999). However, if the more methodologically rigorous half average poverty line is used, there was between 1982 and 1995-96 “... a dramatic one-third drop in before-housing child poverty ...” (Harding \& Szukalska, 1999, p. iii). This is in sharp contrast to experience in 12 other industrialised countries (Bradbury \& Jantii, 1998, cited in Harding \& Szukalska, 1999, p. 30). The other hypotheses advanced by Rutter and Smith (1995b), although all plausible, are equally difficult to substantiate from available Australian data.

One thing that does seem clear is that the marked geographical variations in socioeconomic status across Australia documented recently by Glover et al. (1999) have persisted for many years, and may indeed have increased (Harding, 2000). Moreover, specific areas have been 'high risk' in terms of a range of social, health and economic indicators for at least a quarter of a century (compare Vinson \& Homel, 1975 and Vinson, 1999). Vinson and Homel's original work demonstrated a coincidence of social, health and crime problems in a small number of urban areas, but the same is undoubtedly true in country regions, particularly in Aboriginal communities (Aboriginal and Torres Strait Islander Women’s Task Force on Violence, 1999). Such persistent and marked concentrations of crime and disadvantage in specific localities suggest that whatever preventive initiatives are developed at a whole of population level, there is a special need for joined up solutions in the most disadvantaged communities.

The need for a special focus on high risk localities is underlined by recent large scale research in the United States. Pollard et al. (1999) demonstrated in an analysis of 
questionnaire data from more than 80,000 high school students that there is a strong curvilinear relationship between level of risk (aggregated across individual/peer, family, school and community) and the prevalence of substance use, school problems, and delinquency. Involvement in the less prevalent activities, such as taking a gun to school or delinquency, was particularly high in the highest risk category, leading the researchers to conclude that “... preventive interventions should be focused on geographical areas or populations exposed to high overall levels of risk” (p. 156). Significantly, their data also showed that high scores on protective factors were not sufficient to nullify the impact of a high risk score, although in the two highest risk categories protective factors did have an ameliorative effect. Their conclusion was that a simple focus on "strengthening assets" without also attending to risk exposure is “incomplete as a strategy for reducing the prevalence of problem behaviors” (p. 156).

This conclusion is consistent with findings from a recent analysis of the Pittsburgh Youth Study (Wikström \& Loeber, 1999), which found that living in a very high risk neighbourhood overwhelmed the effects of individual and family protective factors, leading to late onset serious offending by young adolescents who were previously conforming, well-adjusted children. Neighbourhood status had no direct independent effect on early onset offending, but as the authors note probably had substantial indirect effects via its impact on families and the development of "individual dispositions" in early childhood (p. 19). An important implication of this study is that adolescent-limited offending (Moffitt, 1993) in high risk areas may not be prevented by early intervention programs that strengthen protective factors in individuals, families or even contexts like schools unless these programs also influence the dynamics of peer groups and the public settings inhabited by adolescents (see also Wright et al., 1999). 
The creation of more 'child-friendly neighbourhoods' through 'whole of community’ approaches, together with early intervention and cross-sectoral collaboration, has gradually been recognised as a critical ingredient for successful child maltreatment prevention programs (Tomison \& Wise, 1999). Adolescents and their families have naturally been less prominent in these models than families with young children. The recent research evidence suggests that if the child-friendly focus in disadvantaged areas were to be expanded to encompass adolescents and their environments, the potential crime prevention benefits (incorporating short-term as well as long-term results) might be substantially increased.

Perhaps surprisingly, despite a century of research on neighbourhoods, many criminologists have been slow to catch up with these trends in prevention research, which have been strongly influenced by human development scholars such as Bronfenbrenner (1979) and Garbarino (1995). One of the main aims of the Developmental Crime Prevention Consortium (1999) in their Pathways to Prevention report published by the Federal Government was to bring these fields closer together ${ }^{\mathrm{i}}$.

\section{Developmental Prevention}

The overall goal of the Pathways report was to translate developmental prevention planning and implementation from the 'laboratory' to the community. On the one hand there is the world of science, consisting of a small number of carefully designed, thoroughly implemented and rigorously evaluated field interventions. (The recent report

of the US Committee on Integrating the Science of Early Childhood Development, titled From Neurons to Neighborhoods (Shonkoff \& Phillips, 2000) contains a comprehensive 
review of scientific research on early childhood, including the intervention literature.) Examples include the Perry Preschool Project (Weikart \& Schweinhart, 1992), the Elmira Prenatal/ Early Infancy Project (Olds et al., 1999), and the Seattle Social Development Project (Hawkins et al., 1999). On the other hand, there is the 'real world' of disadvantaged communities and routinely delivered government and non-government programs which have wide reach but are seldom if ever evaluated and are only imperfectly influenced by the scientific literature. The Consortium's major task was to integrate diverse theoretical and research literatures to construct a framework for thinking from a developmental perspective about the prevention of crime and associated problems at the local level. The resulting "policy framework” (p. 18) consisted of a series of steps for planning locality-based crime prevention, especially in multi-problem areas.

These steps involve more than “risk focused prevention” (Hawkins \& Catalano, 1992), although this is extremely important, but also the skills to apply developmental thinking creatively in complex local situations. If, for example, one intervenes to alter the route to social status for adolescents away from involvement in gangs or deviant peer groups, alternative pathways to respect must be created (see Developmental Crime Prevention Consortium, 1999, p. 86). How are alternative pathways blocked by doors shut in the face of children or adolescents by inflexible school systems or by other institutions (perhaps reflecting the “one mistake and you're out!” approach to behaviour management)? What can be done, on the basis of developmental and other research, to facilitate movement between life phases (such as the transition to school), especially for ethnic and racial minorities? The questions are endless, but the underlying issues always 
relate to time and to timing, and to the opening up of alternative routes for participation in and control over mainstream institutions.

It will be apparent that a definition of developmental prevention that encompasses all the concepts elaborated in Pathways poses quite a challenge. Nevertheless, a succinct statement that builds on but goes beyond definitions that centre on 'criminal potential in individuals' or on risk and protective factors would have value both for practitioners and for researchers. We have found the following description useful:

Developmental prevention involves intervention early in developmental pathways that lead to crime and related problems, emphasising investment in 'child friendly' institutions, communities and social policies and the manipulation of multiple risk and protective factors at different levels of the social ecology and at crucial transition points, such as around birth, the commencement of school, or graduation from primary to high school.

Certain principles flow from this description. One is that 'early intervention' means 'early in the pathway,' not necessarily early in life. Thus there is room within a developmental framework for adolescent-focused interventions of the kind mentioned earlier. Another is that context is always vital: changing social policies, institutions or neighbourhoods, difficult as this is, is as important as changing individual behaviours. A third principle that turns out to be very useful as a guide for action is to focus on transition points. No one program can cover the waterfront, especially in its early stages, so organising one's thinking around one or at most two key life transitions simplifies the planning task while increasing the chances that interventions will have a high uptake by the target population. A final principle (although more could be extracted) is that risk and protective factors do matter, and that interventions should be selected that have a good chance of shifting a few of them. (How many in one project? 
A rule of thumb seems to be up to six, but this needs a stronger practice base to substantiate it.)

The final step or recommendation of the policy framework proposed in Pathways (Recommendation 16) was that Australia should move toward the design of a community-based project that could demonstrate the application of all the steps and the principles in a small number of disadvantaged areas. A whole of community approach incorporating a range of programs and services was envisaged, rather than a focus on a single program. The "move toward” aspect was emphasised, since the authors expressed doubts that either funding or planning for a major project of this kind could be achieved within a single electoral cycle. Inspiration for the demonstration project idea came from several sources.

The evidence on 'what works' in early intervention was of course fundamental but there were caveats. One problem is that many well-designed programs have a poor take-up rate in disadvantaged areas. For example, Durlak and Wells (1997) in a metaanalytic review of primary prevention mental health programs found that parent training failed to achieve results because very few eligible parents participated. A large-scale community intervention in the US called Children at Risk (Welsh \& Farrington, 1999) also failed due to a very low participation rate. A special issue of the journal Future of Children (1999 XX) summarised recent evidence on the impacts of variety of home visiting programs, finding very wide variation in results with no large or consistent benefits in child development or health behaviours. Key program elements were hard to identify, and there were generally immense problems with implementation and attrition rates. The editors concluded that modest expectations for these kinds of programs are appropriate, and that generalisation across contexts and population groups is not possible. 
A further, perhaps more fundamental question, is whether even successful US programs could ever achieve the same results in Australia, given that the most deprived groups in these studies (amongst whom the most dramatic results are often achieved) are probably worse off than any part of the Australian population (with the probable exception of Aborigines) (Foley et al., 2000). This highlights the need to develop and evaluate home grown initiatives.

A second influence on our thinking was the literature on community organisation or mobilisation, particularly the Communities That Care model pioneered in the US by Hawkins \& Catalano (1992) and now being implemented in the UK (Communities That Care (UK), 1997) and in Australia (Toumbourou, 1999). CTC is a highly rational 'public health' approach that involves the systematic identification and measurement of risk and protective factors in a selected community (utilising mainly official data and a standard questionnaire completed by adolescents), and the selection, implementation and evaluation of appropriate evidence-based interventions by a community prevention board. It is a model that is sufficiently flexible to involve all sectors of a community, and if implemented rigorously should achieve substantial results. CTC has not yet been evaluated as an overall model, although a large-scale evaluation of the CTC program in three communities in the UK is currently underway.

One potential criticism of CTC - whether justified or not - is that it could be rather 'top-down' and 'formula' driven, involving community influentials rather than the 'grass-roots'. A further concern is that risk factors relevant to prevention Community development, the third inspiration for Recommendation 16, is one traditional model for community action that explicitly attempts to resist these tendencies. Community workers seek through participatory processes to redress 
inequality and exclusion, with a focus on groups seen to be marginalised socioeconomically, culturally or politically (Lane \& Henry, 2000). The community development approach has the potential to reach these marginalised groups in ways that often elude more formal programs, perhaps even of a sophisticated variety like CTC. Given the evidence that the most marginalised groups are often most at risk and are the hardest to reach, the blending of community development and developmental prevention models may produce a powerful brew.

It is important to remember, however, that community development cannot be viewed just as a clever technique to enhance program penetration rates. It must be taken on its own terms and used to empower, not to manipulate, disadvantaged groups. Subject to this qualification, community development theory and practice might benefit enormously from an infusion of fresh ideas from developmental psychology and public health, and from a sharp focus on risk and protective factors and on measurement and evaluation. Essentially this means bringing a new kind of resource to disadvantaged communities - the fruits of scientific research. Such research can be a powerful tool facilitating the empowerment of marginalised people, provided resulting programs are understood by, accepted and preferably managed by the relevant groups.

\section{A Toe in the Deep End - Planning for a Community Project}

In this concluding section, we describe briefly some aspects of the development of a project in a disadvantaged area of Brisbane ${ }^{\mathrm{ii}}$. The aim is to implement some of the recommendations of the Pathways report, including a 'scaled down' version of Recommendation 16 . The overall theme (and the name of the project) is simply 
Pathways, reflecting not only our starting point but also (hopefully) a positive orientation connoting a rich variety of possibilities and opportunities.

The project, which at the time of writing (mid-2000) was in a planning and data collection phase, involves a collaboration of Griffith University academics, the national welfare agency Mission Australia, and five state government departments, with input from an expert advisory group drawn from Australia and overseas. The next phase will involve the appointment of project staff and the development of links with the community, with a view to gaining local participation and representation on the project management group. An initial three year project life is envisaged.

The project began because of a 'seeding grant' to Mission Australia by the John Barnes Foundation. The conditions of the grant were that the project should be carried out through schools in disadvantaged areas in Queensland, and that it should "make a difference.” We drew for possible sites from the 12 disadvantaged areas in Queensland designated by the state government as community renewal areas, comparing crime rates and other indicators to make a final choice. It is probable that a second community will be selected as funds become available. The request to work in schools meant that an initial focus for planning has been the six state schools in the selected area and the attached preschools, together with the associated families.

The education focus is a useful point of entry. Hertzman (1999, p. 34), in describing the "pathways model" of human development, underlines the pivotal role of readiness for school and behaviour problems in school. The review of research by Buchanan (1998) confirmed that emotional and behavioural problems increase the risks of educational failure and social exclusion in childhood, and unemployment, mental illhealth and criminal activity in adult life (see also Pavaluri et al., 1996). Others have 
noted that school problems "characterise $80 \%$ or more of serious delinquent youth" (Huizinga \& Jakob-Chien (1998 p. 409). Similarly, findings of the report of the American Psychological Association Commission on Violence and Youth (1993) underscored the relationship between educational failure and antisocial behaviour. In this regard, McCoy and Reynolds (1999) point out that: first, children with language and reading disabilities are at high risk for the development of social and emotional problems: and, second, that studies of children with behaviour problems have found a high incidence of language disorders. That is, there is a high likelihood of the cooccurrence of reading problems, language difficulties and behaviour problems. This research has influenced our thinking about possible preschool- and school-based interventions.

\section{The Area}

The study community is one of the poorest urban areas in Queensland, with half of all dwellings currently Housing Commission stock. Sole parent families are a third of the total, nearly a quarter of the workforce is unemployed, and median household weekly income in 1996 was only \$412, one of the lowest levels in Queensland. Nearly one person in five is a child under the age of 10 . The community is also multicultural, with substantial Vietnamese, Samoan and indigenous populations, and there are tensions and sometimes fighting between different groups of ethnic young people. Significantly, the juvenile crime rate is more than three times higher than any other community renewal area, although the child abuse notification rate is not the highest in 
Brisbane. Exactly half of all convicted juvenile offenders are indigenous, although they comprise fewer than $10 \%$ of the population.

Despite the poverty, the community does have considerable strengths. There is a sense of pride in the area amongst many residents, parks and gardens are attractive (although the sense of 'safety' is less than desirable), school staff are extremely dedicated and committed to the wellbeing of the community, and there are many community and recreational facilities (although according to the teenage population “there’s not enough to do”). Designation as a community renewal area means that state government resources for building physical and social infrastructure will increasingly become available, with a consultant's report on the suburb almost complete. There is also an extremely active network of local service providers and community workers who have compiled extensive data on the community and on the needs of families and children. The existence of several reports on the area means, effectively, that much of the essential data collection and appraisal of community resources has already been completed.

Interestingly, no official data on participation rates in formal preschool programs were available. Our initial estimate from our own survey is that, perhaps surprisingly, around $80 \%$ of Year 1 children have attended preschool, often the one attached to their primary school. However, our impression is that the participation rates of indigenous and Samoan children are somewhat lower. Generally, we are finding that schools and preschools are a 'pressure point' in terms of the impact of poverty and multiculturalism. Schools have to employ bilingual teacher aides as many of the children have limited skills in English. Many also have learning difficulties in their first language, and a number of children are significantly below state norms when they commence preschool. 
The nutrition of children is also a perennial issue. The schools organise meetings with parents to discuss appropriate food, and frequently provide sandwiches for children to ensure they get a proper meal. School excursions, of course, despite being low cost, often do not involve the children who could benefit the most.

\section{The Evolving Model: Child, Family, School and Community}

Without further extensive consultation with parents from all ethnic groups and also with service providers and community workers, it is not possible to state with certainty what programs will be introduced. However, our preliminary work suggests that the general model that is evolving will be acceptable and useful, complementing existing and planned programs in the area. The project focus is children aged three to six years and their families, preschools, childcare centres, schools and, where possible, the wider community. Thus the transition to school is the immediate focus, with enhanced readiness for school a specific goal. We envisage a set of programs divided into two broad, inter-related categories: Family Support and Preschool/ School Programs.

The Family Support programs are conceptualised as consisting of overlapping layers, moving from informal, broad-based programs such as play groups, parenting training, and education forums, to formal support services such as parenting support groups or toy libraries, through to intensive family support and assistance, such as individual and family counselling (Nocella, 1996). Some of these services already exist in the area, many need to be better resourced, while others (as few as possible) will need to be built from scratch. 
One resource we hope to bring to the community is a research base consisting of promising or 'proven' Australian programs. Some programs of this type were reviewed by the Developmental Crime Prevention Consortium (1999) and have developed further since the audit (late 1997). Some have now been evaluated. One example is TUFF Together for Under Fives and Families. This project was established in 1995 in Coonamble, New South Wales. It is a joint project between the Departments of Health, Community Services and School Education, and is part of a broader program known as the Schools as Community Centres Program. The aim of this program is to promote a healthy positive start for children entering school, through inter-agency collaboration and provision of support to families. Outcomes in Coonamble include (amongst many) a significant increase in enrolments in transition to school programs, with early identification of at risk children; increased emergent literacy behaviours; increased involvement of Aboriginal families and workers in developing strategies to meet family needs; and increased age appropriate immunisation ${ }^{\mathrm{iii}}$.

There is a growing consensus amongst researchers that appropriate early learning experiences can act as protective factors, with positive effects upon the cognitive and social development of preschool children to prevent, or allay, serious educational and behaviour problems (Golly et al.,1998; Schweinhart \& Weikart, 1997; Sylva \& Colman, 1998). Research findings have made it clear, however, that not all intervention programs are equally effective in addressing the problems of children with emotional and behaviour difficulties (Barlow, 1998). Analyses of successful programs have revealed that significant elements incorporate a curriculum focus on the specific factors detrimentally affecting social adjustment and educational progress (Sylva \& Colman, 1998), and, as we have seen, a focus on key transition points in the life of the child 
(Golly et al., 1998). Other significant program elements (as in the Schools as Community Centres example) involve intervention at the ecological levels of the parents, family and the wider community, as well as parent and teacher education components (Barlow 1998; Wasserman \& Miller, 1998).

In the light of these significant elements, we are developing a program at the preschool - to - school transition point that has been piloted in Brisbane and subjected to a preliminary qualitative evaluation that showed positive results (Elias \& Taylor, 1995). The research literature strongly suggests that parent-oriented intervention facilitates improved language and literacy outcomes (Edwards, 1995; Snow et al., 1999; Whitehurst et al., 1994). Consequently, a major component of the proposed program concerns the enhancement of parent-child and teacher-child interaction patterns through modifying the adults’ interactive style. In particular, the modifications to adult interactive styles focus on factors relating to children's development of communication and language skills. It has frequently been pointed out that children's oral language skills underpin the development of literacy (Bowey, 1995; O’Connor et al., 1995), and that children from low-income families are often deficient in skills essential to literacy acquisition. In the light of these findings, relevant program elements include training parents in adult-child book reading interactions and in the use of conversational styles of interaction that enhance the development of cognition and language (Dickinson \& Smith, 1994).

It is expected that communication enhancement groups will be conducted in a number of preschools, initially by a teacher with specialist qualifications in this field, but later by other teachers trained by the specialist in the methods. These groups will involve parents with their preschool children and will focus on the development of 
communication skills in play, conversational and book-reading contexts. Allied to this, play groups with similar language and communication goals will be conducted for younger children with their mothers. Communication programs will be developed suited to the particular needs of the parents and children in the various preschool communities (eg., to meet the needs of non-English-speaking parents). All this will be integrated as far as possible with the family support activities, including such practical (but vital) elements as assistance with transport and childcare.

\section{Conclusion}

The locality matters, especially for families with young children. Disadvantaged communities, given their concentration of poverty, crime and child malteatment, matter even more, whatever the larger societal trends toward greater or lesser inequality. Moreover, the impact of neighbourhood organisation and social climate on children and young people, independent of the characteristics of individuals and families, suggests that programs need to be directed at the community itself, not just at the individuals living in it.

The combination of community development and developmental prevention approaches has promise as a way of enhancing the impact of programs in the poorest areas, and genuinely facilitating the move toward independent living by the most disadvantaged families and their children. This 'transition to a new research mode' is fraught with risks - after all, few seem to have gone before, few can provide guidance along the way. So a team effort is required, pooling the skills and insights from many 
disciplines. There must be, as well, a willingness to take risks and make mistakes. But the journey does seem worth undertaking.

\section{Notes}

i The Developmental Crime Prevention Consortium comprised (at the time the Pathways report was prepared) the convenor, Ross Homel (Griffith University), Judy Cashmore (NSW Child Protection Council), Linda Gilmore (UQ), Jacqueline Goodnow and Alan Hayes (Macquarie University), Jeanette Lawrence (Univ. of Melbourne), Marie Leech (Uniya), Ian O’Connor, John Western \& Jake Najman (UQ) \& Tony Vinson (UNSW). ii Since at the time of writing project implementation had not begun, the area is not identified in this chapter. A very real aspect of the disadvantage experienced by residents in the selected area is stigmatisation simply on the basis of address. Managing this image problem will be one of the many challenges to face the project team. iii Updated information on TUFF kindly provided by the Coonamble project team. 


\section{References}

Aboriginal and Torres Strait Islander Women's Task Force on Violence. (1999). Report. Brisbane, Qld: Department of Aboriginal and Torres Strait Islanders.

American Psychological Association, Commission on Violence and Youth (1993).

Violence and Youth: Psychology's Response Vol 1. Washington DC: Author.

Barlow, J. (1998). Parent-training programmes and behaviour problems: findings from a systematic review. In A. Buchanan and B. L. Hudson (Eds), Parenting, Schooling and Children’s Behaviour, pp. 89-109. Sydney: Ashgate.

Bowey, J. A. (1995). Socioeconomic status differences in preschool phonological sensitivity and first-grade reading achievement. Journal of Educational Psychology, $87,476-487$.

Bronfenbrenner, U. (1979). The Ecology of Human Development: Experiments by Nature and Design. Cambridge, MA: Harvard University Press.

Buchanan, A. (1998). A consensus. In A. Buchanan and B. L. Hudson (Eds), Parenting, Schooling and Children’s Behaviour, pp. 178-191. Sydney: Ashgate.

Davison, T., Ferraro, L. \& Wales, R. (2000). Review of the Antecedents of Illicit Drug Use With Particular Reference to Adolescents. Unpublished paper, University of Melbourne.

Developmental Crime Prevention Consortium. (1999). Pathways to Prevention: Developmental and Early Intervention Approaches to Crime in Australia. Canberra: National Crime Prevention. 
Dickinson, D.K. \& Smith, M.W. (1994). Long-term effects of preschool teachers’ book readings on low-income children’s vocabulary and story comprehension. Reading Research Quarterly, 29, 105-122

Durlak, J. A. (1998). Common risk and protective factors in successful prevention programs. American Journal of Orthopsychiatry, 68(4), 512-520.

Durlak, J. \& Wells, A. (1997). Primary prevention mental health programs for children and adolescents: A meta-analytic review. American Journal of Community Psychology, 25(2): 115-152.

Edwards, P.A. (1995). Empowering low-income mothers and fathers to share books with young children. The Reading Teacher, 48, 558-564.

Elias, G. \& Taylor, E. (1995). Report of the Review of the Logan West Language Skills Program. Brisbane: Faculty of Education, Griffith University.

Foley, D., Goldfield, S., McLoughlin, J., Nagorcka, J., Oberklaid, F., \& Wake, M. (2000). A Review of the Early Childhood Literature. Canberra: Department of Family and Community Services.

Garbarino, J. (1995). Raising Children in a Socially Toxic Environment. San Francisco: Jossey-Bass.

Glover, J., Harris, K. \& Tennant, S. (1999). A Social Health Atlas of Australia. Volume 1: Australia. Canberra: Public Health Information Development Unit.

Golly, A. M., Stiller, B., \& Walker, H. M. (1998). First Step to Success: Replication and social validation of an early intervention program. Journal of Emotional and Behavioural Disorders, 6(4), 243-250.

Harding, A. (1997). The suffering middle: Trends in income inequality in Australia, 1982 to 1993-94. The Australian Economic Review, 30(4), 341-58. 
Harding, A. (2000). Opinion: Swill time for those at the top. Canberra: National Centre for Social and Economic Modelling.

Harding, A. \& Szukalska, A. (1999). Trends in Child Poverty in Australia: 1982 to 1995-96. Discussion Paper No. 42. Canberra: National Centre for Social and Economic Modelling.

Hawkins, D. \& Catalano, R. (1992). Communities That Care. San Francisco: JosseyBass.

Hawkins, J. D., Catalano, R. F., Kosterman, R., Abbott, R., \& Hill, K. G. (1999). Preventing Adolescent Health-Risk Behaviours by Strengthening Protection During Childhood. Archives of Pediatrics and Adolescent Medicine, 153(3), 226-234.

Hertzman, C. (1999). Population health and human development. In D. Keating \& C. Hertzman (eds.), Developmental Health and the Wealth of Nations: Social, Biological and Educational Dynamics (pp. 21-40). New York: Guilford.

Homel, R. \& Bull, M. (1996). 'Under the influence': Alcohol, drugs and crime. In K. Hazlehurst (ed.), Crime and Justice: An Australian Textbook in Criminology (pp. 151-178). Law Book Co.

Homel, R. \& Mirrlees-Black, C. (1997). Assault in Queensland. Brisbane: Qld Criminal Justice Commission (12 pages).

Huizinga, D. \& Jakob-Chien, C. (1998). The contemporaneous co-occurrence of serious and violent juvenile offending and other behavior problems. In R. Loeber and D. P. Farrington (Eds), Serious and Violent Juvenile Offenders (pp. 47-67). London: Sage.

Keating, D. P., \& Hertzman, C. (Eds.). (1999). Developmental Health and the Wealth of Nations: Social, Biological and Educational Dynamics. New York: Guilford. 
Lane, M. \& Henry, K. (2000). Community development, crime and violence: A case study. Unpublished paper, Department of Social Work, Social Policy \& Sociology, Universityof Sydney.

McCoy, A. R. \& Reynolds, A.J. (1999). Grade retention and school performance : an extended investigation. Journal of School Psychology, 37, 273-298.

Marshall, J., \& Watt, P. (1999). Child Behaviour Problems: A Literature Review of the Size and Nature of the Problem and Prevention Interventions in Childhood. Perth, WA: The Interagency Committee on Children's Futures.

Moffitt, T. (1993). Adolescence-limited and life course-persistent antisocial behavior: A developmental taxonomy. Psychological Review 100(4): 674-701.

Nocella, L. (1996). Strengthening Families Program: An Initiative of the Port Adelaide Central Mission - External Evaluation Report, June 1995 - July 1996. Adelaide: University of South Australia.

O’ Connor, R. E., Jenkins, J. R. \& Slocum, T. A. (1995). Transfer among phonological tasks in kindergarten: essential instructional content. Journal of Educational Psychology, 87, 202-217.

Olds, D. L., Henderson, C. R., Kitzman, H. J., Eckenrode, J. J., Cole, R. E., \& Tatelbaum, R. C. (1999). Prenatal and infancy home visitation by nurses: Recent findings. The Future of Children, 9, 44-64.

Pavaluri, M. N., Luk, S-N \& McGee, R. (1996). Help-seeking for behavior problems by parents of preschool children: a community study. Journal of the American Academy of Child and Adolescent Psychiatry, 35, 215-223. 
Pollard, J. A., Hawkins, J. D., \& Arthur, M. W. (1999). Risk and protection: Are both necessary to understand diverse behavioral outcomes in adolescence? Social Work Research, 23, 145-158.

Rutter, M. \& Smith, D.J. 1995. Towards causal explanations of time trends in psychosocial disorders of youth. In M. Rutter \& D.J. Smith (Eds.), Psychosocial disorders in young people: Time trends and their causes (pp. 782-808). New York: John Wiley \& Sons.

Schweinhart, , L. J. \& Weikart, D. P. (1997). Lasting differences: the High/Scope Perry preschool curriculum comparison through age 23. Ypsilanti, Michigan: High Scope Press.

Shonkoff, J.P. \& Phillips, D.A. (Eds.), 2000. From neurons to neighbourhoods: The science of early childhood development. Washington, D.C.: National Academy Press.

Smith, D.J. \& Rutter, M., 1995. Time trends in psychosocial disorders of youth. In M. Rutter \& D.J. Smith (Eds.), Psychosocial disorders in young people: Time trends and their causes (pp. 763-781). New York: John Wiley \& Sons.

Snow, C.E., Burns, M.S. \& Griffin, P. (1999). Preventing Reading Difficulties in Young Children. Washington, D.C.: National Academy Press.

Sylva, K. \& Colman, P. (1998). Preschool intervention to prevent behaviour problems and school failure. In A. Buchanan and B. L. Hudson (Eds), Parenting, Schooling and Children’s Behaviour, pp. 178-191. Sydney: Ashgate.

Tomison, A. M., \& Wise, S. (1999). Community-based approaches in preventing child maltreatment. National Child Protection Clearinghouse Issues Paper, 11, 1-19. 
Toumborou, J. W. (1999). Implementing Communities that Care in Australia: A community mobilisation approach to crime prevention. Trends and Issues in Crime and Criminal Justice No. 122. Canberra: Australian Institute of Criminology.

Vinson, T. (1999). Unequal in Life: The Distribution of Social Disadvantage in Victoria and New South Wales. Melbourne: Jesuit Social Services.

Vinson, T. \& Homel, R. (1975). Crime and disadvantage: the coincidence of medical and social problems in an Australian city. The British Journal of Criminology, 21-31.

Wasserman G. A. \& Miller L. S. (1998). The prevention of serious and violent juvenile offending. In R. Loeber and D. P. Farrington (Eds), Serious and Violent Juvenile Offenders (pp. 197-247). London: Sage.

Weikart, D. \& Schweinhart, L. (1992). High/Scope preschool program outcomes. In J. McCord \& R. Tremblay (Eds.), Preventing Antisocial Behaviour: Interventions From Birth Through Adolescence. New York: Guilford.

Welsh, B. C., \& Farrington, D. P. (1999). Delinquency prevention using family-based interventions. Children and Society, 13(4), 287-303.

Whitehurst, G.J., Arnold, D.S., Epstein, J.N., Angell, A.L., Smith, M.\& Fischel, J.E. (1994). A picture book reading intervention in day care and home for children from low-income families. Developmental Psychology, 30, 679-689.

Wikström, P. \& Loeber, R. (1999). Do disadvantaged neighborhoods cause welladjusted children to become adolescent delinquents? A study of male juvenile serious offending, individual risk and protective factors, and neighborhood context. Unpublished paper, Institute of Criminology, University of Cambridge. 
Wright, B. R. E., Caspi, A., Moffitt, T. E., \& Silva, P. A. (1999). Low self control, social bonds and crime: Social causation, social selection, or both? Criminology, 37(3), 479-514.

Zubrick, S., Silburn, S., Vimpani, G. \& Williams, A. (1999). Emergent demand for measurement indicators of social and family functioning. In Report of a National Workshop on Indicators of Social and Family Functioning, 12-12 April 1999 (pp. 1138). Canberra: Commonwealth Department of Family and Community Services. 